\title{
HOW CAN LIGHT ART MANIPULATE THE VISUAL PERCEPTION OF SPACE?
}

\author{
Zahra RAHIMI and Laila STEEN \\ Oslo Metropolitan University, Norway
}

\begin{abstract}
Transitioning from a field of engineering to a medium for more artistic expressions, lighting has changed from strictly functional lightboxes to elaborate light-based designs and installations. Both artists and architects have used light as a medium to manipulate visual perception and impressions. This paper explores the interaction between light, visual perceptions, and space. Through a case study of artworks that experiment with light, space, and visual perceptions, it discusses how light art can impact perceptions by the way it illuminates spaces. The findings demonstrate the impressions and perceptions created by light art and coloured light as an artistic material. The aesthetic application of light can remove boundaries and define a space in a different way. Although lighting installations are primarily part of architecture and interior design, this article proposes how light can be applied in design by manipulating the visual perception of the design on users.
\end{abstract}

Keywords: Light, space, visual perception, colour, impression

\section{INTRODUCTION}

Light creates the aesthetical and functional aspects as a physical and dynamic medium to highlight the essential details and materials of space [9]. It adds an intangible explanation to space and object, which is more adaptable to change in comparison with other materials in space [12]. Moreover, light is a vital factor of designs and art installations, as it can affect the experience of the space for the viewer [13]. Visual perception is the interplay of light and surface in space [16], and brightness is the consequence of this interaction [14]. This brightness makes an impression that is equally determined with perception status and luminance level [12].

Light characterizes space in addition to fulfilling the visual needs [16]. It can identify the unique character of space by emphasizing its perceptual qualities. This significant role of light makes it a medium to present the design ideas to the viewer and impact the cultural psyche of a society [9]. The common aspects of light in art, design, and architecture, in addition to existing knowledge of its psychological impressions, convey a need for further investigation into the intensity of the visual perception for viewer [16]. Therefore, it is necessary to understand the impact of the interplay between light, material, and visual perception to enhance the viewer's response to object and space [14].

\section{BACKGROUND}

\subsection{Light and visual perception}

Light enables vision in a meaningful connection with the world through the fact that people respond to the space based on the way the light exposes it to them [14]. Accordingly, both natural and artificial light might influence visual perception and how space is perceived [9]. This phenomenon can illustrate the components by emphasizing form, texture, create a mood in addition to determining the borders of the space [14]. It also defines the sense of space by changing the boundaries in the space and make impressions [19].

Light can be experienced intellectually as well as sensationally [9]. People's perception and response to space can be manipulated as the light changes in that space, and more than that, the impression can change as well [14]. This perception can differ from person to person. According to phenomenology studies, perception can also emerge from past experiences. By reducing past considerations, the reality 
of the present moment can be experienced. This has become an idea for light and space artists to create perceptual isolation by removing sensory distractions [16].

\subsection{Light art}

By the end of the 20th century, the nature of artificial light was discovered as a medium in combination with other materials by many artists [16]. Modernism inspired the changes that occurred in the form of light as lightboxes and using light instead of colour to create the illusion of the space. This transition to light-based creations marked the beginning of using light differently in art as a medium to manipulate perception and senses [16]. As Weibel and Jansen (2006) mentioned, "Pure light gained the status of a material which is used as a sole matter of the art piece. Interest shifted from what is illuminated in the space to how space is illuminated" [16].

The emergence of qualitative approaches to the use of light was the reason of its progression from only being a field of engineering to a creative discipline [12]. The idea of site-specific installations was introduced by Dan Flavin (1933-1996), as a space constructed specially for the artist to use light to model the artwork. It was the beginning of expanding light spaces into creating visual perceptions [16]. To create the light spaces, artists of light and space try to benefit from the eye's ability to adapt to the light and darkness. This sensitivity can be applied in two ways, the first one increasing the light slowly while the viewer is in the dark space, the second one conducts the viewer immediately from a darkness to a bright space [16].

\section{METHODOLOGY}

\subsection{Case study and observation}

The selected methods to conduct the research in this article were case study and observation. Two cases were studied through these methods to address their exceptional qualities for similar and future situations and designs. Additionally, there were an investigation into details of historical, inspirational, and influential aspects through documents, websites, and articles [15]. Closer analysis and observation were conducted to collect data on the physical environment, impacts, and interactions [15]. To explore the knowledge outlined about light art, the chosen cases are Skyspace artwork by James Turrell and Hyundai capital convention hall by the Gensler design group.

\section{CASE STUDY}

\subsection{SKYSPACE}

In the old water reservoir of Ekeberg sculpture and national heritage park in Oslo, Norway, the American artist James Turrell (b.1943) created two light installations in 2013. The artist named Ganzfeld as Double Vision, and Skyspace as The Colour Beneath [17]. As New Yorker critic Calvin Tompkins wrote, light has the physical presence in Turrell's installations to create the visual impression of the space [11]. James Turrell has used the interplay of light, colour, and space to affect the limits of human perception [3]. He believed that if people understand the physical presence of light, they value it as much as gold and silver [2].

\subsubsection{Double vision}

In the Ganzfeld installation, Turrell was inspired by a psychological experiment with the same title, to create a similar experience by filling the field of vision with colour. Ganzfeld is a German word to characterize the sensory phenomenon of losing depth perception as in the experience of colour vision loss (a whiteout) [10]. Ganz translates to the whole or entire, and Feld translates to field or area. This defines a homogeneous visual field [18]. Furthermore, this visual field on a surface without determined boundaries is known as the Ganzfeld effect [6].

As Turrell stated, he designed and controlled the space by making the eyes try to focus while no details and objects other than smooth white surfaces and diffused light exist (Figure1\&2). Coloured light is his medium to get the viewers to integrate with his work. He has tried to make them "look at their looking," as he calls it, while they are unable to describe their thoughts verbally [11]. In the description of his works, he explains that: "My works are not a looking at, but a looking into; not the displacement of space with mass, but the working of space; not objects in a room, but the room. The format is not things within space, but space itself." [1]. 


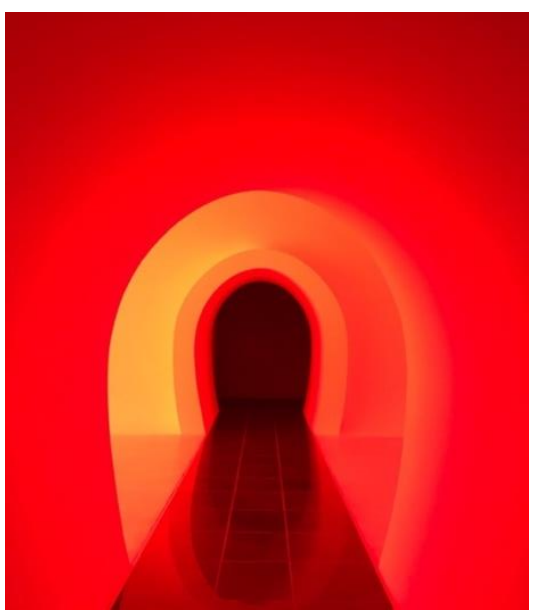

Figure 1. "Ganzfeld", 2019

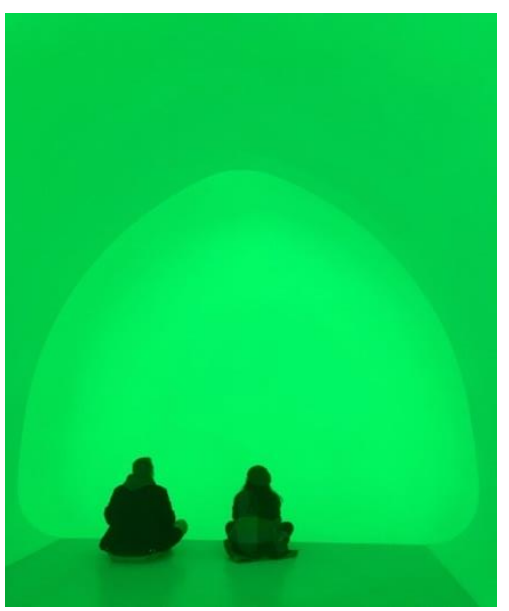

Figure 2. "Ganzfeld", 2019

\subsubsection{The colour beneath}

Turrell uses the sky as his canvas within the Skyspace to displays the notion of reality and colours created by viewers' perception [11]. As the artist stated, he tried to create perception art by making the human experience in the reality of seeing and not an object to experience [8]. Experiencing the Skyspace installation is the same as looking at a piece of art, but the experience is looking at the viewer's perception [2].

Sitting in a circular space, while looking directly at the sky through an opening in the ceiling with the lights changing colours in the space, makes the perception different [4]. The experience is about having different perceptions of the sky distance from your place while being indoor [2]. The sky without any objects such as clouds or stars looks transparent, but it also illustrates the homogeneous visual field as Ganzfeld. This perception makes the relationship between these two installations [1].

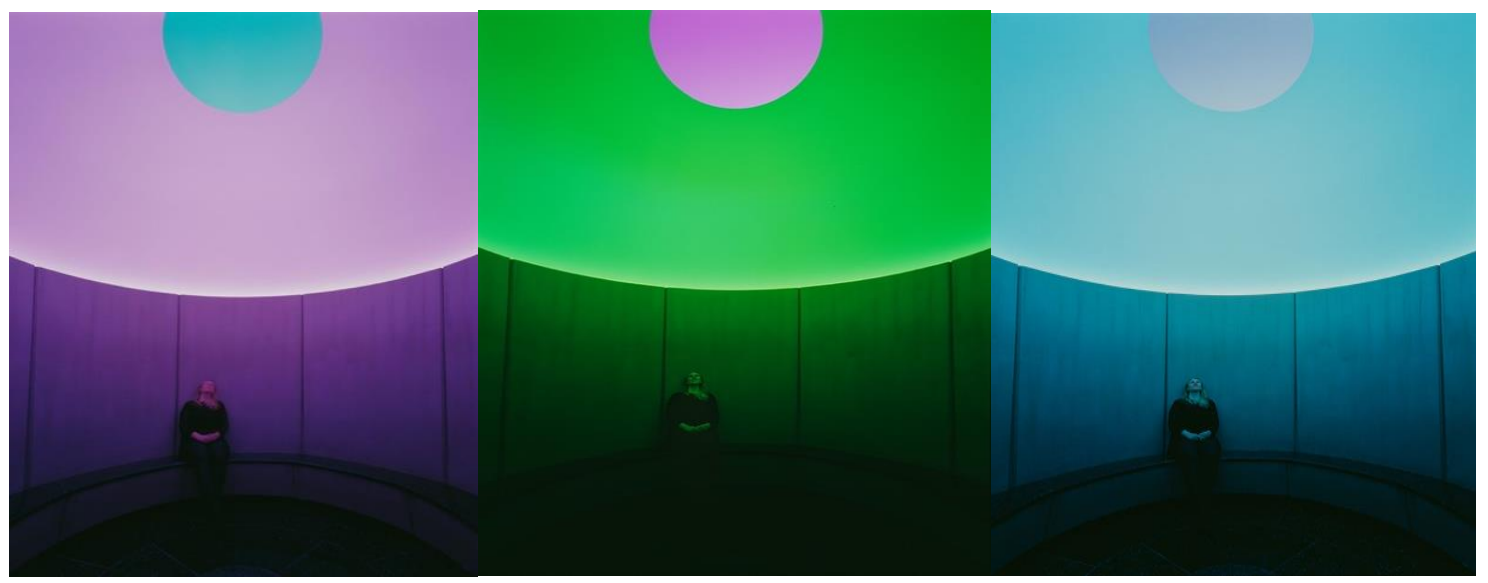

Figure 3. "Skyspace; The Colour Beneath, Oslo" 2013

The interplay between natural and artificial light from inside of the space challenges the perception of light amount from each source [4]. Placing light with complementary colours in the space makes those colours seem brighter. By adding a brighter or white colour, all the colours adjust to that colour, and in this way, the visual system dedicates light values to different parts of the space (Figure.3). Light artists use this visual system of the human as Turrell in Skyspace [16]. Turrell also stated that: "My work is more about your seeing than it is about my seeing, although it is a product of my seeing. I'm also interested in the sense of the presence of space; that is space where you feel a presence, almost an entity - that physical feeling and power that space can give." [11]. 


\subsubsection{Observation of SKYSPACE by James Turrell}

The first illustration of this artwork installation is a dark entrance passage, which aim seems to be to prepare the viewer by contrasting between outdoor and indoor. It is followed by a large room surrounded by smooth matt white surfaces and without any sharp corners, making it challenging to recognize the intersections of walls, floor, and ceiling (Figure 1). Ganzfeld is created from two egg shapes halves placed on each side of the installation (Figure 2). The first experience makes the viewers ask themselves: in a room without any object or specific detail, what are they supposed to look at?

A closer inspection, such as trying to touch the egg shape walls reveals the reality that there is endless and empty space in front of you, rather than a simple wall. This is the experience of losing depth perception. By changing the light colour continuously and slowly, the perception and the dimension of the depth become more challenging to comprehend. Although the eyes adjust to the lights change, this perception of depth and absorption continues. Also, the white colour of the walls in this space is increasing the light's colour intensity while eliminating the shadows.

By going through another dark space to the next installation, the Skyspace can be explored as a circleshaped space. This space consists of concrete walls from the floor and continues as a white and plastered wall to a circular opening overhead, looking up directly to the sky. The opening is without obstruction or transparent glass, and the interior of Skyspace is only surrounded by stone benches in a circular shape except for the entrance. Light fixtures are hidden and oriented toward the opening. It can be observed that James Turrell is not only the creator of light perception in his spaces but also the architect and designer of these spaces as he works with the material in addition to light. The experience of the Skyspace would start with silence on the base of experiencing inner peace. It continues by questioning the distance of the sky, which seems to be closer than the real distance by looking from inside. Besides, the perception that the blue illustration in the ceiling opening is the real sky and not just a blue surface or painting on the surface.

\subsection{Hyundai Capital Convention Hall}

On the top of the south tower of Hyundai Capital's global headquarter in Seoul, the 6,250 square-foot assembly space was completed in the summer of 2016 by the Gensler design group. This new hall was aimed to deface the lines between art and architecture by manipulating the user's perception of material, light, and space. The design was aimed to create a timeless space without boundaries [5]. This project was nominated for interior architecture by AIA awards in 2019 [7] and the best use of innovative lighting by Frame awards 2020 [5]. This project is designed to be flexible for hosting a wide range of activities, including training sessions, company meetings, client presentations, guest lectures, and parties in addition to expressing the essence of Hyundai minimalist and progressive brand [5]. The interior consists of an artistic installation from James Turrell (Figure 4), a classic photography cyclorama, and a moulded acoustical plaster shell form by Gensler designers [7]. The design team used layers of innovative light design as indirect sources to illuminate glowing arches while adding a visual perception to space (Figure 5) [5]. They also used light and colour to make a contrast in the presentation room with black colour and LED light lines [5].

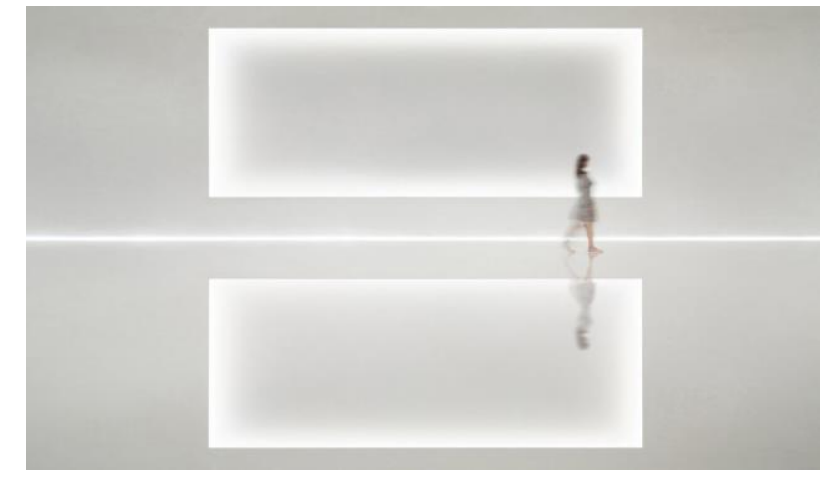

Figure 4. James Turrell Installation in Hyundai Capital Convention Hall 


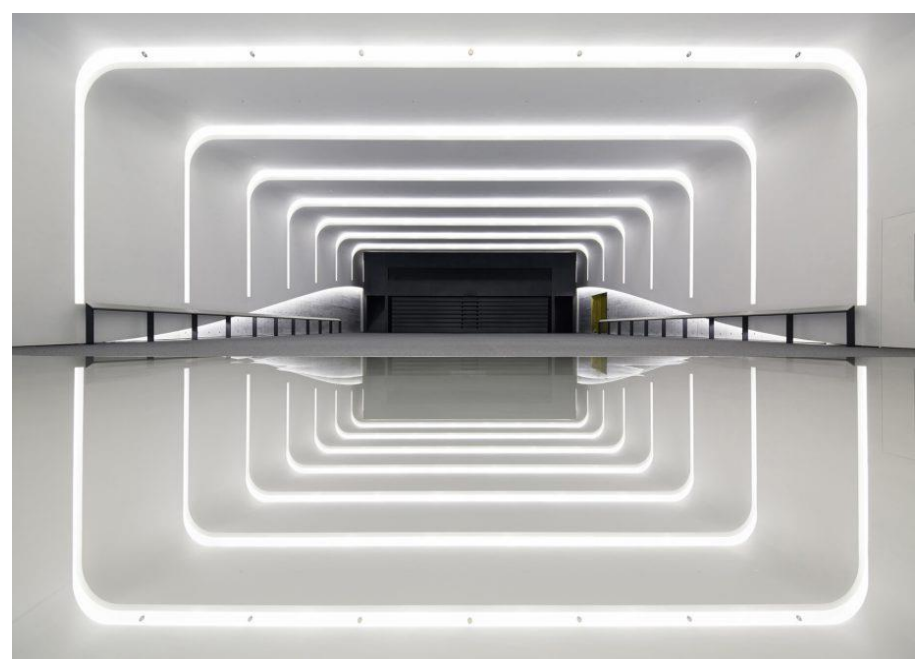

Figure 5. Innovation Lighting in Hyundai Capital Convention Hall

\section{DISCUSSION}

The case studies of The Colour Beneath in the Skyspace installation reveals the intention of visual perception in a sensible way. Ganzfeld indicates the light as a material used by the artist to conduct the viewer's concentration in experiencing the space. For this reason, the focus point on this installation is light and how various colours of light aesthetically manipulate the boundaries of the artwork. The definition of the light in this space insists on the visual sense as the only tool of perception adapting to different levels of light and colour.

The Skyspace case study illustrates the integration of natural and artificial light and its impact on the visual system. The illustration of the sky characterizes the role of light in creating perception. As observed in these case studies, there is a balance between light and viewer perception. This balance can support the combination of lighting quality, space characters, and visual perceptions. According to the space design, with no objects to focus on, and shifting light colours as common characters, the emotional responses and perceptions are different. More than that, border, limitation, and shadow become meaningless. The artist highlighted the characteristic of light in the space to create different perceptions. In the Hyundai Capital Convention hall, the design tried to alter the perception of the space by using light and colour contrast. This contrast seems to be used to make emphasis some parts of the space and, at the same time, use the minimalist character of the colours, material, and form. Also, by blurring the intersections and transforming the space to a shimmering white shell to challenge the idea of boundaries, the designer added an aesthetic, artistic aspect to the interior architecture.

\section{CONCLUSIONS}

The underlying intentions of lighting are to elicit an emotional or perceptual response, which insists on the idea that light art is not only about the space but also the user or viewer. Lighting art can aesthetically define the visual perception of space outlines. These approaches can change the space experience and distinguishes the artistic application of light from a purely technical one. The character of light as a subjective material in space also has a significant role in architecture and design. Architects and lighting designers need to use the psychological, visual, and artistic aspects of light to describe the design concept. This would help the user to communicate appropriately with the surroundings. Different perceptual experiences will occur because of the context of the individual viewer, what they perceive and to what extent that matches with the main concept.

With the awareness of its impact on visual perception and knowledge of its psychological impressions, product designers should acknowledge the perceptual experience of light in making products. Therefore, it can be used effectively to manipulate the complexity of the environment for the user. As some of the recent light products are more than a feature to illuminate and formed as a sculpture and art piece which can impact the visual perception by the way it defines in the space. Using these aspects of light in products in addition to aesthetic aspects of the design can be a promotive solution for improved product experience. 


\section{REFERENCES}

[1] Adock, C. James Turrell: The Art of Light and Space. 1990 (University of California press, Berkeley California).

[2] Art21, Inc.(producer). Second Meeting. [Video Clip]. Available: https://www.lacma.org/art/exhibition/james-turrell-retrospective [Accessed on 2019, 21 October], (2013) 17 May.

[3] Ekebargparken. James Turrell Ekeberg Skyspace and Ganzfeld. Available: https://ekebergparken.com/nb/kunst/skyspace-og-ganzfeld [Accessed on 2019, 18 October], (2019).

[4] Ekebargparken. Skyspace. Available: https://ekebergparken.com/nb/skyspace-5 [Accessed on 2019, 18 October], (2019).

[5] Frame Publishers. Hyundai Capital Convention Hall, Seoul. Available: https://frameawards.com/winners/93416-hyundai-capital-convention-hall [Accessed on 2020, 28 February], (2020).

[6] Gadassik, A. Perceptual Cells: James Turrell's Vision Machines Between Two Paracinemas. Leonardo. 2016, 49(4), 306-316. doi:10.1162/LEON_a_01283.

[7] Gensler. Hyundai Capital Convention Hall. Available: https://www.gensler.com/projects/hyundai-capital-convention-hall [Accessed on 2020, 28 February], (2020).

[8] Govan, M. James Turrell. Available: https://www.interviewmagazine.com/art/james-turell\#_ [Accessed on 2019, 15 October], (2011).

[9] Ippolito, P. Designing Interior Architecture: Concept, Typology, Material, Construction. 2013 (Birkhäuser. Basel).

[10] James Turrell. Ganzdeld. Available: http://jamesturrell.com/work/type/ganzfeld/ [Accessed on 2019, 20 October], (2019).

[11] James Turrell. Introduction. Available: http://jamesturrell.com/about/introduction/ [Accessed on 2019, 20 October], (2019).

[12] Karcher, A., Krautter, M., Kuntzsch, D., Schielke, T., Steinke, C., \& Takagi, M. Light and Dark. Light Perspectives: Between Culture and Technology: Light, Space, Perspectives. 2009 (Erco, Lüdenscheid).

[13] Karlen, M., Benya, J., \& Spangler, C. Lighting Design Basics. 2012 (Wiley, Hoboken, N. J).

[14] Livingston, J. (2014). Designing with Light: The Art, Science, And Practice of Architectural Lighting Design. 2014 (John Wiley \& Sons, Inc., Hoboken, N. J).

[15] Muratovski, G. Research for Designers: A Guide to Methods and Practice. 2016 (Sage Publications., Los Angeles).

[16] Nikolic, B. Light Art in Contemporary Architectural Lighting Design (Master's Thesis) 2017 (School of Architectural and the Built Environment, KTH, Stockholm).

[17] Rellihan, K. How to Find James Turrell's Art in The Most Unlikely Corners of The Earth. Available: https://www.architecturaldigest.com/story/james-turrell-art-around-the-world [Accessed on 2019, 20 October], (2018).

[18] Wackermann, J., Putz, P. \& Allefeld, k. Ganzfeld-induced hallucinatory experience, its phenomenology and cerebral electrophysiology. Cortex, 2008, 44(10), 1364-1378. doi: 10.1016/j.cortex.2007.05.003.

\section{ILLUSTRATIONS}

[1] Ekebargparken. Skyspace; The Colour Beneath (2013) Ekebergparken, Oslo, Norway.@ James Turrell Available: https://ekebergparken.com/en/skyspace-6 [Accessed on 2019, 20 October], (2019).

[2] Frame Publishers. Hyundai Capital Convention Hall, Seoul. ( ) NACASA AND PARTNERS Available: https://frameawards.com/winners/93416-hyundai-capital-convention-hall [Accessed on 2020, 28 October],(2020). 